\title{
The Difference of Perceived HIV Stigma between People Living with HIV Infection and Their Families
}

\author{
Kusman Ibrahim $^{1}$, Rita Kombong ${ }^{2}$, Aat Sriati ${ }^{1}$ \\ ${ }^{1}$ Faculty of Nursing, Universitas Padjadjaran, Indonesia \\ ${ }^{2}$ Master of Nursing Program, Universitas Padjadjaran; Nurse at RSUD dr.M. Haulussy, \\ Maluku, Indonesia \\ Corresponding Author: Kusman Ibrahim (kusman_ibrahim@yahoo.com)
}

Received: 16 July 2019

Revised: 13 October 2019

Accepted: 27 December 2019

\begin{abstract}
Background: The stigma of HIV and AIDS become a significant barrier to prevention, treatment, and care for HIV infected people. Disclosure of HIV status to the family can help People Living with HIV infection (PLWH) to obtain support and comfort from their family. However, the difference of perceived HIV stigma held by patients and families has become problematic and lead to inadequate responses of PLWH and their families.

Purpose: This study aimed to examine the difference in perceived HIV stigma between PLWH and their families.

Methods: This was a cross-sectional study involving 60 respondents that consisted of 30 PLWH and 30 family members. They were recruited purposively in an HIV clinic of a residencial hospital in West Java Province, Indonesia. The perceived HIV stigma was measured by the Berger's HIV stigma scale (BHSS), and the Liu's Courtesy Stigma Scale (LCSS) was used to measure the perceived HIV stigma at the family level. Data were analyzed using descriptive and inferential analysis (independent t-test) to test the difference in perceived HIV stigma between PLWH and their families.

Results: The study found that most PLWH and their families perceived HIV stigma at a moderate level (70\% vs. $63.4 \%$, respectively). There was a significant difference in perceived HIV stigma between PLWH and their families $(t=3.4 ; p=0.001)$. The PLWH perceived HIV stigma was higher than their family members $(M=41, S D=13.9$ vs. $M=28.5, S D=14.0$ ).

Conclusion: This study highlighted that PLWH and their family have different perceptions regarding HIV stigma, which can lead to different responses. Therefore, nurses and other health care providers need to be aware and take a comprehensive assessment-related perceived HIV stigma in order to provide a high quality of nursing care, mainly dealing with HIV stigma for both PLWH and their family members.
\end{abstract}

Keywords: Family, perceived HIV stigma, PLWH

How to cite: Ibrahim, K., Kombong, R., \& Sriati, A. (2019). The difference of perceived HIV stigma between people living with HIV infection and their families. Nurse Media Journal of Nursing, 9(2), 117-127. doi:10.14710/nmjn.v9i2.24256

Permalink/DOI: https://doi.org/10.14710/nmjn.v9i2.24256 


\section{BACKGROUND}

Human Immunodeficiency Virus (HIV) remains a major challenge for health development in many countries. HIV has changed gradually from an acute fatalistic disease to a manageable chronic disease that requires lifelong treatment and care for PLWH (people living with HIV) in order to maintain their health and quality of life (Swendeman, Ingram, \& Rotheram-Borus, 2009). Currently, approximately 37.9 million people were living with HIV infection throughout the world (UNAIDS, 2019). Indonesia is a country known as the world's fastest-growing epidemics of HIV from very few people with HIV in 2000 to an estimated 640,000 in 2018 (UNAIDS, 2019). West Java Province is the most populous province in Indonesia, which has a high number of PLWH. It is estimated that there were 36,853 PLWH in West Jawa from 1987 until June 2019, which constituted the third-largest number of PLWH after Jakarta and East Java Province (Ministry of Health Republic of Indonesia [MoHRI], 2019). The increasing number of PLWH has raised the burden on individual, family, and community life and nation development (Ibrahim \& Songwathana, 2009). Based on the evaluation of the three 'zero' program; zero new HIV infection, zero HIV discrimination, and zero AIDS-related deaths, those goals have not been successfully achieved globally (UNAIDS, 2017). Discrimination toward PLWH remains to exist in family, community, even in health care settings and institutions. There was evidence that 1 out of 10 PLWH has reported lost their source of income due to their HIV status (UNAIDS, 2017). In addition, free from AIDS-related death has not been achieved successfully; yet it declined to one million in 2016. Therefore, there is an increasing concern if those ambitious goals also could not be achieved in the extension period that has been agreed by the United Nation's country members to be achieved by 2030 .

The perception of HIV stigma is a significant barrier in prevention, treatment, and care for PLWH. In India, a study revealed that stigma became a barrier to health and wellbeing for patients with HIV, especially among HIV infected women (Yakhmi, Sidhu, Kaur, \& Dalla, 2014). In Indonesia, a previous study found that some people showed negative attitudes such as refused to eat food provided or sold by PLWH, not allowing their children to play with children of HIV infected parents, not using shared toilets, and refusing to stay close with PLWH (Shaluhiyah, Musthofa \& Widjanarko, 2015).

PLWH encountered not only physical problems related to the disease but also social problems as a consequence of bearing the disease. The perception toward HIV stigma can be referred to as the assessment of people who are HIV infected, which includes negative attributes or characteristics by which they are treated differently from other community members (Earnshaw \& Chaudoir, 2009). As the perception of HIV stigma was held by PLWH themselves, it could hinder PLWH from getting access to health care services (Swendeman et al., 2009). The HIV stigma perception of PLWH, or in another term called as personal stigma, is a negative perception of PLWH about themselves that linked to the community's view on HIV as a deadly disease or dirty disease associated with free sex or illegal sexual relation (Earnshaw \& Chaudoir, 2009).

Family is the first line and the closest social environment where HIV infected people live. Family is expected to give support and comfort when their member was diagnosed with HIV and experienced its signs and symptoms throughout the disease process. 
However, some families of PLWH showed negative attitudes and discriminating behaviors when they knew their member was HIV positive. HIV stigma at a family level can be an external stigma that may contribute to a higher perceived stigma by PLWH. Family stigma represents a negative view of the family toward PLWH, which leads to discrimination behaviors due to disease status (Greeff et al., 2008). Cultural related factors and family's functioning and development are also influencing factors to the perceived HIV stigma among family members (De Wet, Du Plessis, \& Klopper, 2013). The different perceptions of HIV stigma between PLWH and their family may also inhibit PLWH to disclose their HIV status to family members due to fear of rejection and discrimination by family members (Gari, Habte, \& Markos, 2010). In fact, disclosing HIV status is very important to plan appropriate treatment, care, and support for PLWH. Understanding perceptions of HIV stigma between PLWH and their families become a crucial element for designing appropriate interventions in caring for PLWH and their families.

\section{PURPOSE}

This study aimed to examine the differences in perceptions of HIV stigma between PLWH and their families.

\section{METHODS}

\section{Design and sample}

The study used a cross-sectional design with a comparative method approach. Thirty PLWH and 30 family members were recruited purposively to participate in this study. Inclusion criteria for being a PLWH respondent were their age $\geq 18$ years, or adult, be able to read, write, and communicate well in Bahasa Indonesia, and not suffering from mental disorders. Meanwhile, family members involved in this study were those who live with patients in the same household for at least one month, knowing the patient's HIV status, able to read, write, and communicate well in Bahasa Indonesia.

\section{Ethical consideration}

Ethical approval of the study was obtained from the Health Research Ethics Committee of the Faculty of Medicine, Universitas Padjadjaran (Letter number: 057/UN6.KEP/EC/2018). Permission to collect the data was granted by the hospital director, where the study took place. Ethical principles were assured not to be violated throughout the study process.

\section{Measurement}

The perception of HIV stigma on PLWH was measured by using Berger's HIV stigma scale - Indonesian version (BHSS-I), which has been translated and validated by Nurdin (Berger, Ferrans, \& Lashley, 2001; Nurdin, 2013). The BHSS-I has a Cronbach's alpha coefficient of 0.94 for a total score of 40 items, and 0.81 to 0.92 for sub-scales, indicating that the instrument has strong validity and reliability. The BHSS-I measured personal stigma, status disclosure, negative self-image, and public attitudes. It consisted of 40 items with a 4-point ordinal response scale ranging from strongly disagree, disagree, agree, and strongly agree. The total lowest score was 40, and the total highest score was 160. The total score was then categorized into three levels: mild (40-80), moderate (81-120), and severe (121-160) (Charles et al., 2012; Li \& Sheng, 2014). 
Construct validity of the BHSS was supported by relationships with related constructs: self-esteem, depression, social support, and social conflict. Coefficient alpha was 0.96 meaning that the instrument has high internal consistency reliability (Berger et al., 2001).

Family's perception regarding HIV stigma was measured by using Liu's Courtesy Stigma Scale (LCSS); it measured both public and self-perceived stigma (Liu, Xu, Sun, $\&$ Dumenci, 2014). It consisted of 22 items with a 4-point ordinal response scale from strongly disagree, disagree, agree, and strongly agree. The total score ranged from 22 to 88, which was divided into three levels: mild (22-40), moderate (41-60), and heavy (6188) (Singh, Chaudoir, Escobar, \& Kalichman, 2011). The Cronbach's alpha coefficient of the original LCSS was between 0.83 to 0.90 , which was considered as reliable instrument with good construct validity. The original questionnaire was written in English; therefore, it was translated into Bahasa Indonesia using a back-translation technique by experts who are fluent in both languages. The translated instrument was reviewed and modified in order to fit with the targeted population.

\section{Data analysis}

In the univariate level, data were analyzed by calculating frequency and percentage for each level of perceived stigma and its components for both PLWH and family respondents. In the bivariate level, an independent t-test was employed to examine the differences in perceived stigma between PLWH and family. Before comparing the means scores of perceived HIV stigma between PLWH and family, each data score was transformed into 100 formula (score $100=100 \times$ (individual score - lowest score) / range) for each respondent (McDowell, 2006).

\section{RESULTS}

\section{Demographic characteristics of respondents}

The study involved 60 respondents that consisted of 30 PLWH and 30 family members. Respondents of PLWH were predominantly 26-35 years of age group, male, completed junior high school, self-employed, unmarried, Muslim, and on Antiretroviral Treatment (ART) medication. Moreover, the family member group was dominated by 26-35 years of age group, female, completed junior high school, self-employed, married, Muslim, and in a family relationship as a parent (Table 1).

Table 1. Demographics characteristics of respondents $(n=60)$

\begin{tabular}{lcc}
\hline Characteristics & PLWH (n=30) & $\begin{array}{l}\text { Family }(\mathrm{n}=30) \\
f(\%)\end{array}$ \\
\hline Age (Years) & $f(\%)$ & $7(23.3)$ \\
$\quad 18-25$ & $9(30)$ & $14(46.7)$ \\
$26-35$ & $15(50)$ & $9(30)$ \\
$\quad 36-45$ & $6(20)$ & $16(53.3)$ \\
Sex & $7(23.3)$ & $14(46.7)$ \\
$\quad$ Female & $23(76.7)$ & $7(23.3)$ \\
$\quad$ Male & $6(20)$ & \\
Education & & \\
$\quad$ Elementary School & & \\
\end{tabular}




\begin{tabular}{lcc}
\hline Characteristics & PLWH $(\mathrm{n}=30)$ & Family $(\mathrm{n}=30)$ \\
& $f(\%)$ & $f(\%)$ \\
\hline Junior High School & $8(26.7)$ & $13(43.3)$ \\
Senior High School & $12(40)$ & $8(26.7)$ \\
Academic/University & $4(13)$ & $2(6.7)$ \\
\hline Occupation & & \\
Self-employed & $24(80)$ & $3(46.7)$ \\
Private employee & $3(10)$ & $13(43.3)$ \\
Housewife & $3(10)$ & \\
Marital Status & & $20(66.6)$ \\
Married & $6(20)$ & $8(26.7)$ \\
Unmarried & $21(70)$ & $2(6.7)$ \\
Widower/Widow & $3(10)$ & $30(100)$ \\
Religion & $30(100)$ & $0(0)$ \\
Islam & $0(0)$ & - \\
Non Islam & & \\
ART medication & $30(100)$ & \\
Yes & $0(0)$ & $7(30)$ \\
No & - & $8(26.3)$ \\
Family Relationship & - & $6(20)$ \\
Parents & - & \\
Spouse (Husband-Wife) & - & \\
Sibling (Younger - Older) & & \\
Children &
\end{tabular}

\section{Perceived HIV stigma}

Table 2 presents the level of perceived stigma and its components between PLWH and family. Most PLWH respondents and family perceived stigma within a moderate level. Personal stigma was dominated by the stigma component among PLWH, while the proportion of self-perceived stigma was higher than public stigma among family respondents.

Table 2. Level of perceived HIV stigma and its' components between PLWH and families $(n=60)$

\begin{tabular}{lcll}
\hline \multicolumn{1}{c}{ Perceived HIV stigma } & $\begin{array}{l}\text { Mild } \\
\mathrm{f}(\%)\end{array}$ & $\begin{array}{l}\text { Moderate } \\
\mathrm{f}(\%)\end{array}$ & $\begin{array}{l}\text { Heavy } \\
\mathrm{f}(\%)\end{array}$ \\
\hline PLWH: & $9(30)$ & $21(70)$ & $0(0)$ \\
$\quad$ Overall & $8(26.7)$ & $22(73.3)$ & $0(0)$ \\
Personal stigma & $10(33.3)$ & $20(66.7)$ & $0(0)$ \\
$\quad$ Status disclosure & $9(30)$ & $21(70)$ & $0(0)$ \\
$\quad$ Negative self-image & $9(30)$ & $19(63.3)$ & $2(6.7)$ \\
$\quad$ Social attitudes & & & \\
Family: & $11(36.6)$ & $19(63.4)$ & $0(0)$ \\
$\quad$ Overall & $20(66.7)$ & $10(33.3)$ & $0(0)$ \\
Public stigma & $19(63.3)$ & $11(36.7)$ & $0(0)$ \\
$\quad$ Self-perceived stigma & & & \\
\hline
\end{tabular}

Because of the different number of items between the BHSS and LCSS, in order to make it appropriate for comparison, the raw data of each respondent were transformed 
into a 100-formula. The mean score, standard deviation, and range for each group were calculated before and after transformation (Table 3).

Table 3. Transformation of data score of perceived HIV stigma between PLWH and families

\begin{tabular}{llcc}
\hline & Mean & SD & Range \\
\hline PLWH: & & & \\
$\quad$ Before transformed & 89.2 & 16.7 & $58-115$ \\
After transformed & 41 & 13.9 & $15-63$ \\
Family: & & & \\
$\quad$ Before transformed & 40.9 & 9.3 & $22-57$ \\
$\quad$ After transformed & 28.5 & 14.0 & $0-53$ \\
\hline
\end{tabular}

\section{The difference of perceived HIV stigma between PLWH and families}

Before comparing the means score between PLWH and family groups, the researchers conducted a normality test using the Shapiro Wilk technique. The test revealed p-value $=0.63$ for PLWH, and 0.31 for the family, which could be concluded that the data were normally distributed ( $p>0.05)$. The homogeneity test was performed by using Levene's test and the result showed p-value $=0.997(>0.05)$, which indicated that there was a similarity of variances or homogeneity was assumed. The steam-leaf and box-plot were checked, and the results showed none outlier data were identified. Therefore, all assumptions of independent t-test have been met. The result found that there was a significant difference in perceived HIV stigma between PLWH and their families ( $p$ > 0.05), with a mean score of PLWH was higher than their family (Table 4).

Table 4. The difference of perceived HIV stigma between PLWH and families

\begin{tabular}{lllll}
\hline Perceived stigma & Mean & SD & $t$ & $p$ \\
\hline Overall score: & & & & \\
PLWH & 41 & 13.9 & 3.4 & 0.001 \\
Family & 28.5 & 14.0 & & \\
\hline
\end{tabular}

\section{DISCUSSION}

HIV-related stigma is still prevalent among society, although much significant progress has been made in the medical treatment of the disease. The stigma attached to HIV/AIDS is even considered being higher than other diseases such as leprosy, which caused bodily disability (Stevelink, Van Brakel \& Augustine, 2011). It is due to negative views and judgments on individuals' behaviors who contracted the disease (Lindberg, Wettergren, Wiklander, Svedhem-Johansson, \& Eriksson, 2014). Stigma toward HIV may occur at various levels, including personal, family, community, and public levels.

On the other hand, the stigma can also exist in different settings such as education, workplaces, health care services, even in legal and policy institutions. This study found that most PLWH respondents and their families perceived HIV stigma at a moderate level. The stigma component among PLWH dominated personal stigma. This is relevant to previous studies in China and India reporting that most of PLWH respondents in the 
studies rated their HIV stigma as a moderate level (Li \& Sheng, 2014; Gohain \& Halliday, 2014). Stigma can be changed in many ways, but the most popular intervention is by educating people with accurate information and knowledge about HIV through multiple channels of educational media.

Considering that nowadays there are many media available that provide information and knowledge related to HIV and easily accessible by the public, it has likely succeeded in improving the public's knowledge about HIV and reducing HIV stigma level compared to the beginning era of the HIV epidemic. However, it did not totally eradicate the stigma; it is remaining to exist though in the level of moderate and lower. Personal stigma was found as the highest number compared to other stigma elements among PLWH in this study. Personal stigma, or in another term known as internal stigma refers to thoughts and behaviors came from negative perceptions of his/her own individuals which are an essential part of mental health for individuals' adaptation in their life (Kalichman et al., 2009). Perceived internal stigma can be manifested in forms of feeling shame, guilty, lonely, or depressed that make individuals isolated from others (Cameron et al., 2011; Nachega et al., 2012). In this study, personal stigma was higher than other elements within a moderate level; however, the range among these stigma elements is not very wide. It means PLWH have all stigma elements that contributed to their perception of HIV stigma. In the family group, the proportion of the moderate level of self-perceived stigma was higher than public stigma. It is similar to a study from Vietnam that found perceived HIV stigma by the family of PLWH was dominantly moderate (Lundberg et al., 2016). Public stigma can be understood as the attitudes or reactions that the general people demonstrate to PLWH as felt by the family of PLWH. In contrast, the self-perceived stigma refers to the fear of societal attitudes and potential discrimination perceived by the family who have a family member with HIV/AIDS (Liu et al., 2014). Self-perceived stigma was identified as a higher proportion because the family seemingly has more thought about the stigma rather than their real experience of encountering stigma from the community.

This study revealed a significant difference in perceived HIV stigma between PLWH and their families; the mean score of PLWH was higher than their families. This finding is congruent to a previous study reporting that there was a difference in perceptions toward HIV stigma between PLWH and their family, where PLWH had 2.5 times higher perceived HIV stigma than their family (Liu, Xu, Lin, Shi, \& Chen, 2013). Different perceptions related to HIV stigma may be associated with different levels of education, route of transmission, beliefs, and views regarding HIV and AIDS (Li \& Sheng, 2014; Ibrahim \& Songwathana, 2009). In this study, the majority of PLWH respondents completed senior high school. Although it is not clear the correlation between formal education and level of knowledge about HIV and AIDS, there was evidence that most PLWH in a district hospital in West Java, have lower health literacy (Kesumawati, Ibrahim, Witdiawati, 2019). Health literacy is one of the important factors that influence the perception and behaviors of PLWH. Another study in Bandung, West Java, found that PLWH in a Muslim community perceived HIV and AIDS as a deadly, dirty, and horrifying illness due to deviant behaviors of free sex, or using illicit drugs as the risk factors of getting HIV infection (Ibrahim, 2010). It reflected the influence of cultural beliefs and the context of Islamic teaching that 
emphasized prohibiting free sex and taking illicit drugs that is considered as a big sin. It is relevant to a previous study highlighting the influence of family race, cultural values, and religious and spiritual values on HIV stigma in South Africa (Browna, BeLueb, \& Airhihenbuwaa, 2010). Perceived HIV stigma of PLWH that is higher than the family often hinder PLWH to disclose their status to their family. Ibrahim, Rahayuwati, and Herliani (2019) reported their qualitative findings, which outlined four major themes as reasons for PLWH not to disclose their HIV status to their family. They were (1) negative feelings about being an HIV-infected person, (2) feeling fear of being rejected by family members, (3) avoiding being a burden on the family, (4) desiring to maintain a good relationship with family members. These reasons may also relate to high perceived stigma among PLWH; in fact, it may or may not be the same as the family perceived.

Family is a social structure and environment that closest to PLWH. Impacts of being HIV infected people are not only experienced by PLWH themselves but also experienced by their family members. Goffman (as cited in Liu et al., 2014) pointed out that perceived or experienced stigma could be passed on to family members of those with the stigmatizing attributes. It was named as "courtesy stigma" which refers to a person who perceives or experiences stigmatization due to their association with a person who accepts the punished attribute. Courtesy stigma causes feelings of social isolation, shame, and fear, and introduces additional stressors to HIV-uninfected family members of PLWH. In this regard, the family of PLWH also becomes the subject of stigmatization. This study found that there were two types of perceived stigma that may exist in the family of PLWH, they were public stigma, which was real stigmatization received by the family from neighbors or community, and self-perceived stigma, which was family's perception toward their family members infected by HIV. It can be manifested through discriminating behaviors, responses, negative feelings, and isolation toward PLWH. Nurses as the front line of health care providers who have close contact with PLWH and their families need to have a better understanding of HIV stigma perceived by PLWH and their family.

This study has limitation for generalization to all PLWH population. It is due to only involved one site of HIV clinic and the samples were not recruited randomly. However, this study provide evidence that PLWH and their family have different perceptions regarding HIV stigma, which can lead to different responses.

\section{CONCLUSION}

This study found that most PLWH and their families have perceived HIV stigma at a moderate level. Personal stigma was a higher type of stigma elements reported by PLWH respondents, whereas in the family respondents found that the proportion of selfperceived stigma was higher than public stigma. There was a significant difference in perceived HIV stigma between PLWH and their family with a mean score of PLWH was higher than their family. This study recommends nurses and health care providers to be aware and take a comprehensive assessment-related perceived HIV stigma in order to provide a high quality of nursing care, mainly dealing with HIV stigma for both PLWH and their family members. It would be challenging for further study to cover a wider multisite study with random sampling method validate the results of the study. 
Further study is also needed to investigate factors associated to the difference perceived stigma between PLWH and their family in order to addrees in developing nursing interventions.

\section{ACKNOWLEDGMENT}

The authors would like to thank the Indonesian Ministry of Health, Human Resources Development Agency (BPSDM) through the Maluku Provincial Health Office for funding support to this study. The authors also thank the management of BLUD Banjar Hospital and staffs, as well as all respondents and other parties who have supported and facilitated the study.

\section{CONFLICT OF INTEREST}

The authors declare no conflict of interest.

\section{REFERENCES}

Berger, B. E., Ferrans, C. E., \& Lashley, F. R. (2001). Measuring stigma in people with HIV: psychometric assessment of the HIV stigma scale. Research in Nursing \& Health, 24(6), 518-529. Doi: 10.1002/nur.10011

Browna, D.C., BeLueb, R., \& Airhihenbuwaa, C.O. (2010). HIV and AIDS-related stigma in the context of family support and race in South Africa. Ethn Health, 15(5), 441-458. doi:10.1080/13557858.2010.486029

Cameron, S. (2011). People Living with HIV Stigma Index: Asia Pacific Regional Report 2011. UNAIDS. Retrieved on June 20th 2019 from https://www.aidsdatahub.org/sites/default/files/documents/People_Living_with_ HIV_Stigma_Index_Asia_Pacific_Regional_Report_2011.pdf

Charles, B., Jeyaseelan, L., Pandian, A. K., Sam, A. E., Thenmozhi, M., \& Jayaseelan, V. (2012). Association between stigma, depression and quality of life of people living with HIV/AIDS (PLHA) in South India-a community-based crosssectional study. BMC Public Health, 12(463), 1-11. doi:10.1186/1471-2458-12463

De Wet, G. E., Du Plessis, E., \& Klopper, H. C. (2013). HIV-positive patients' and their families' comprehension of HIV-and AIDS-related information. Health SA Gesondheid (Online), 18(1), 1-11. doi:10.4102/hsag.v18i1.597

Earnshaw, V. A., \& Chaudoir, S. R. (2009). From conceptualizing to measuring HIV stigma: a review of HIV stigma mechanism measures. AIDS and Behavior, 13(6), 1160-1177. doi:10.1007/s10461-009-9593-3

Gari, T., Habte, D., \& Markos, E. (2010). HIV positive status disclosure among women attending art clinic at Hawassa University Referral Hospital, South Ethiopia. East African Journal of Public Health, 7(1), 87-91.

Gohain, Z., \& Halliday, M. A. L. (2014). Internalized HIV-stigma, mental health, coping and perceived social support among people living with HIV/AIDS in Aizawl District-A pilot study. Psychology, 5(15), 1794-1812. doi:10.4236/psych.2014.515186

Greeff, M., Phetlhu, R., Makoae, L. N., Dlamini, P. S., Holzemer, W. L., Naidoo, J. R., ... \& Chirwa, M. L. (2008). Disclosure of HIV status: experiences and perceptions of persons living with HIV/AIDS and nurses involved in their care 
in Africa. Qualitative Health Research, 18(3), 311-324. doi:10.1177/1049732307311118

Ibrahim, K. (2010). Muslim cultural care for people living with HIV infection. (Unpublished PhD Thesis). Prince of Songkla University, Thailand.

Ibrahim, K., \& Songwathana, P. (2009). Cultural care for people living with HIV/AIDS in muslim communities in Asia: A literature review. Thai Journal of Nursing Research, 18(2), 148-157.

Ibrahim, K., Rahayuwati, L., \& Herliani, Y.K. (2019). Barriers to disclose HIV status to family members among People Living with HIV. Jurnal Keperawatan Soedirman, 14(2), 96-102.

Kalichman, S. C., Simbayi, L. C., Cloete, A., Mthembu, P. P., Mkhonta, R. N., \& Ginindza, T. (2009). Measuring AIDS stigmas in people living with HIV/AIDS: The internalized AIDS-related stigma scale. AIDS Care, 21(1), 87-93. doi:10.1080/ 09540120802032627.

Kesumawati, R., Ibrahim, K., and Witdiawati, W. (2019). Literasi kesehatan orang dengan HIV/AIDS [Health literacy among people with HIV/AIDS]. Jurnal Pendidikan Keperawatan Indonesia, 5(1), 77-88

Li, Z., \& Sheng, Y. (2014). Investigation of perceived stigma among people living with human immunodeficiency virus/acquired immune deficiency syndrome in Henan province, China. International Journal of Nursing Sciences, 1(4), 385-388. doi:10.1016/j.ijnss.2014.10.019.

Lindberg, M. H., Wettergren, L., Wiklander, M., Svedhem-Johansson, V., \& Eriksson, L. E. (2014). Psychometric evaluation of the HIV stigma scale in a Swedish context. PloS One, 9(12). doi:10.1371/journal.pone.0114867.

Liu, H., Xu, Y., Lin, X., Shi, J., \& Chen, S. (2013). Associations between perceived HIV stigma and quality of life at the dyadic level: The actor-partner interdependence model. PLoS One, 8(2), e556860. doi:10.1371/journal.pone.0055680

Liu, H., Xu, Y., Sun, Y., \& Dumenci, L. (2014). Measuring HIV stigma at the family level: Psychometric assessment of the Chinese Courtesy Stigma Scales (CCSSs). PloS One, 9(3), e92855. doi:10.1371/journal.pone.0092855

Lundberg, P. C., Doan, T. T. K., Dinh, T. T. X., Oach, N. K., \& Le, P. H. (2016). Caregiving to persons living with HIV/AIDS: Experiences of Vietnamese family members. Journal of Clinical Nursing, 25(5-6), 788-798.

McDowell, I. (2006). Measuring health: A guide to rating scales and questionnaires (1st eds). NY: Oxford University Press.

Ministry of Health Republic of Indonesia (MoHRI). (2019). Laporan perkembangan HIV-AIDS dan Penyakit Infeksi Menular Seksual (PIMS) Triwulan II tahun 2019 [Report on the progress of HIV-AIDS and Sexual Transmitted Diseases in the quarter II-2019]. Jakarta: Direktorat Jenderal Pencegahan dan Pengendalian Penyakit, Kemenkes RI.

Nachega, J. B., Morroni, C., Zuniga, J. M., Sherer, R., Beyrer, C., Solomon, S., ..., \& Rockstroh, J. (2012). HIV-related stigma, isolation, discrimination, and serostatus disclosure: A global survey of 2035 HIV-infected adults. Journal of the International Association of Physicians in AIDS Care, 11(3), 172-178. Doi: $10.1177 / 1545109712436723$ 
Nurdin, A. (2013). Uji validitas dan reliabilitas Berger HIV Stigma Scale versi Bahasa Indonesia dalam menilai perceived stigma pada orang dengan HIV/AIDS (ODHA) [Testing the validity and reliability of Berger HIV Stigma Scale Indonesia Version to evaluate perceived stigma among people living with HIV/AIDS]. (Medical Specialty Thesis). Universitas Indonesia, Jakarta, Indonesia.

Shaluhiyah, Z., Musthofa, S. B., \& Widjanarko, B. (2015). Community stigma towards people living with HIV / AIDS. Public Health: National Public Health Journal, 9(4), 333-339. doi:10.21109/kesmas.v9i4.740.

Singh, D., Chaudoir, S.R., Escobar, M.C., \& Kalichman, S. (2011). Stigma, burden, social support, and willingness to care among caregivers of PLWHA in homebased care in South Africa. AIDS Care, 23, 839-845. doi:10.1080/09540121.2010.542122

Stevelink, S. A. M., Van Brakel, W. H., \& Augustine, V. (2011). Stigma and social participation in Southern India: Differences and commonalities among persons affected by leprosy and persons living with HIV/AIDS. Psychology, Health \& Medicine, 16(6), 695-707.

Swendeman, D., Ingram, B. L., \& Rotheram-Borus, M. J. (2009). Common elements in self-management of HIV and other chronic illnesses: an integrative framework. AIDS Care, 21(10), 1321-1334. doi:10.1080/09540120902803158.

UNAIDS (2017). Global AIDS monitoring. Geneva: UNAIDS. Retrieved from https://www.unaids.org/sites/default/files/media_asset/2017-Global-AIDSMonitoring_en.pdf

UNAIDS (2019). Global HIV \& AIDS statistics - 2019 fact sheet. Retrieved on December 20th, 2019 from https://www.unaids.org/en/resources/fact-sheet

Yakhmi, S., Sidhu, B. S., Kaur, B., \& Dalla, E. K. (2014). Study of HIV related stigma in people living with HIV/AIDS (PLHA): Role of gender differences. Indian Journal of Scientific Research, 5(2), 35. 